\title{
Information Aggregation of Group Decision-Making in Emergency Events"
}

\author{
Kefan Xie, Qian Wu, Gang Chen, Chao Ji \\ Management school, Wuhan University of Technology, Wuhan, China \\ E-mail:xkf@whut.edu.cn, shashavio@sohu.com, \{cg224,jichaowuqiao2003\}@163.com \\ Received May 14, 2010; revised June 22, 2010; accepted July 19, 2010
}

\begin{abstract}
Information is a key factor in emergency management, which helps decision makers to make effective decisions. In this paper, aiming at clarifying the information aggregation laws, and according to the characteristic of emergency information, information relative entropy is applied in the information aggregation to establish the information aggregation model of emergency group decision-making. The analysis shows that support and credibility of decision rule are the two factors in information aggregation. The results of four emergency decision-making groups in case study support the analysis in the paper.
\end{abstract}

Keywords: Emergency, Group Decision-Making, Information Aggregation, Relative Entropy

\section{Introduction}

As an important part of the emergency management, decision-making system for emergency response is one of the most important research areas. Emergency decision-making is a group decision-making process. Emergency managers make decision in the situation of constraint time, incomplete and inaccurate information. They brainstorm and coordinate the interests of multiple decision-makers, in order to handle variety of emergency for achieving timely, effective and smooth goal. Group decision-making behavior in emergency management attracts more and more attention of the whole society.

When making decisions on complex issues, in order to scientific decision-making and avoid individual subjective judgments, choice and preference impact on the decision results, emergency managers should analysis, judgment and decision by adopting integrated experience and wisdom of expert groups and method of group decision-making. Information aggregation has a significant effect in the process of group decision-making, which becomes a hot topic on the emergency management research.

According to information aggregation research, American scholar Yager [1] proposes Ordered Weighted Averaging Operator. Bodily [2] gives information aggregation method based on principal process. Brock [3] puts forward information aggregation method based on NashHarsanyi negotiation model. Krzyszto and Duck [4] propose the information aggregation on the basis of group *Project No. 90924010 supported by NSFC. value judgment. Chen Dongfeng et al. [5] make an uniformization of four common preference information given by decision makers, which are real value, interval values, language phrases and intuitionistic fuzzy value, based on conversion of formula between deferent fuzzy preference information. Li Bingjun and Liu Sifeng [6] construct a defining-number judgment matrix of certain credibility which is equivalent to group information of interval number reciprocal judgment matrix based onset-valued statistics principle. Wu Jiang and Huang Dengshi [7] construct the relation functions based on four interval number preference information, namely interval number preference orderings, interval number utility values, interval number complementary judgment matrices and interval number reciprocal judgment matrices, which uniforms different uncertain preference information. Zhou Shizhong et al. [8] analysis characteristics of four kinds uncertain preference and propose a goal programming model to aggregate the group preference. Zhu Jianjun [9] studies the group aggregation approach of interval number reciprocal comparison matrix and interval number complementary comparison matrix by using UOWA method. Feng Xiangqian et al. [10] construct an aggregating of interval number judgment matrixes with maximum satisfaction. Guiwu Wei [11] proposes intui- tionistic fuzzy ordered weighted geometric operator and interval-valued intuitionistic fuzzy ordered weighted geometric operator to study multiple attribute group decision making issue. H. J. Zimmermann and P. Zysno [12] representing the criteria (subjective categories) 
by fuzzy sets which is possible to use aggregation operators as models for the amalgamation of those criteria. Xie Kefan and Chen Gang [13] research on the entrepreneurial Team's Risk Decision-Making Process Based on Group Learning.

In short, most scholars have focused on the various structural preference aggregation methods. However, the information aggregation has been little studied in emergency cases.

\section{Information Aggregation Mechanism of Group Decision-Making in Emergency Management}

Whether emergency decision making is a scientific decision, depends on whether there is a consistence between quality of information and preference information of expert decision-making. Quality of decision-making information is critical to the ways of group decision-making. Quality of decision-making information refers to the authenticity and credibility of the information. Information aggregation refers to the process of gathering, compressing, screening, refining and integrating to decisionmaking information, which includes aggregation to decision-making information and aggregation to expert preference information. Aggregation to decision-making information composes of information awareness and screening.

Information aggregation of group decision-making in emergency management has two characteristics as follow: 1) Emergency decision-making actors are large groups, which are collections of various groups. Therefore, information aggregation among groups should be taken into account when study on group decision-making; 2) There are two factors to be considered in group decisionmaking: statutory decision-making power and expert decision-making power. Statutory decision-making power is mainly used in emergency decision-making mechanism, and expert decision-making power is mainly used in credibility and support of expert decision-making.

\subsection{Information Perception}

After the outbreak of unexpected events, the interests of all groups would like to obtain the original information as much as possible to make a scientific decision-making to respond to emergency in order to protect their own interests, reduce the loss of harm. Information perception is the first act of information aggregation stage, which refers to the process of getting information by interest groups through various channels and means. The amount of information increases exponentially and generates information associated with variation and deviation after the outbreak of unexpected events, which may bring a lot of information garbage. The information in this stage is incompleteness, and transmission route owns of characteristics of plurality, asymmetry and mutagenicity etc. In this stage, information aggregation of interest groups reflects in the "quantity", which means that obtaining information the more the better and as soon as possible.

\subsection{Information Screening}

Information screening is the second stage of information aggregation. Information screening refers to information process of screening, identification, verification of its authenticity, validity to the first stage perceptible information through various technical means which based on laws and rigorous, serious, scientific workflow. Information screening includes two parts of information process control and information content control. Information screening is the screening authenticity of information in essence in order to ensure the validity of the information. At this stage, each group pays more attention to false, unrealistic and not useful information. After screening the authenticity and validity of information greatly increased and becomes an important basis for group decision-making. Information screening methods can be summarized into two parts. On the one hand it can be judged by perceptions and experiences of decision makers; on the other hand, it can be judged by analyzing, summarizing and organizing the various historical data of past emergency events to find all kinds of information regularity. Information aggregation at this stage of information gathering reflected in the "quality", which means that the more real the obtained information, the better the efficiency will be.

\subsection{Preference Information Aggregation}

In the process of emergency decision-making, in order to ensure scientific decision-making, group decision-making is usually required, that is to focus and synthesize the experience and knowledge of experts, to analyze the problem, judging and decision-making. Group decision making is the essence of decision-makers in each assembly group preferences for the group of decision makers' preferences, then depending on the group's preferences on a set of programs to sort, select the group from which is the most preferred option. Decision information can be incomplete and asymmetric, as well as decision-makers may have different knowledge structure, judgment level and personal preference etc., therefore, when facing the same decision issue experts may give difference preference information of difference structure form, which need to have aggregation process to the preference information. The usual method is to do different forms of preference information consistent processing. The common decision-making preference information can be su- 
mmarized into four types, interval preference order, interval utility value, interval number reciprocal comparison matrix and interval number complementary comparison matrix. Currently, the main methods to synthesis expert opinion and preference in group decision-making can be divided into two categories: Comprehensive Judgment Matrix and Comprehensive sequencing vector. Preference information aggregation is a method of decision makers to take some form of the above or any particular form of individual preferences for the group preference aggregation process. However, the However, the different structure of preference information of the process the same information to generate distortion is inevitable, how to ensure the validity of the information would be an important issue.

\section{Information Relative Entropy Aggregation Model of Group Decision-Making in Emergency Events}

\subsection{Model Assumes}

1) In the process of decision-making in emergency management, assuming that $n$ groups decision of the emergency response form $n$ decision table. Suppose $T$ is decision table set $T_{j}=\left(U_{j}, C \cup\{d\}\right), j=1,2, \cdots, n$, $T=\left\{T_{1}, T_{2}, \cdots, T_{n}\right\}$, where decision table $T_{j}$ of certain group $j$ corresponds to $m_{j}$ decision-making rule, any of which $R u_{i j}=\left\{\operatorname{rule}_{i j}=\operatorname{des}\left([x]_{C_{i j}}\right) \rightarrow \operatorname{des}\left([x]_{d_{i j}}\right)\right\}$ has support $S D_{i j}$ and credibility $C D_{i j}$;

$$
\begin{aligned}
& \text { Then }_{S D_{i j}}=\left|[x]_{C_{i j} \cap d_{i j}}\right| /\left|U_{j}\right| \\
& C D_{i j}=\left|[x]_{C_{i j} \cap d_{i j}}\right| /\left|[x]_{C_{i j}}\right|
\end{aligned}
$$

2) In the process of decision-making in emergency management, there are communication and games among all the groups, which can aggregate $m$ decision rule of group, where any decision-making rule $R u_{i}$ of group has support $S D_{i}$ and credibility $C D_{i}$.

3) In the process of decision-making in emergency management, assuming that any group weight is $\omega_{j}$, then, group decision-making weight distribution is

$$
\omega=\left\{\omega_{1}, \omega_{2}, \cdots, \omega_{j}, \cdots, \omega_{n}\right\} .
$$

Theorem 1: The number of group decision rule $m$ is greater than or equal to the number of any group decision-making rule $m_{j}$ in group, that is $m_{j} \leq m$.
Certification: Assuming that $m_{j}$ decision rules of group $j$ can form decision-making system of $S_{j}=$ $\left(U_{j}, C \cup\{d\}\right)$. Therefore, in the decision-making system, if $\exists x_{1 j}, x_{2 j} \in U_{j}$ as well as $x_{2 j} \in\left[x_{1 j}\right]_{C}$, then it is inevitable that $x_{2 j} \notin\left[x_{1 j}\right]_{d}$, that is the decision system is incompatible, and there are $m_{j}$ decision rules to meet the conditions. Assume that group decision-making system is $S=(U, C \cup\{d\})$, then $S_{j} \subseteq S$ is inevitable. Assuming that $S-S_{j}$ is one of decision-making system, if $\exists x \in U-U_{j}, \quad \exists x_{j} \in U_{j}$ as well as $x \in\left[x_{j}\right]_{C}$, $x \notin\left[x_{j}\right]_{d}$, then group decision-making system $S=$ $(U, C \cup\{d\})$ is incompatible and there are more than $m_{j}+1$ decision rules to meet the condition, that is $m=m_{j}+1>m_{j}$; If $\forall x \in U-U_{j}, \exists x_{j} \in U_{j}$ as well as $x \in\left[x_{j}\right]_{C}, x \in\left[x_{j}\right]_{d}$, then decision-making system $S-S_{j}$ and $S_{j}=\left(U_{j}, C \cup\{d\}\right)$ is fully compatible, but there are at least $m_{j}$ decision-making rules, that is $m=m_{j}$, so $m_{j} \leq m$.

\subsection{Support and Credibility of Decision Rule}

For $m_{j} \leq m$, group $j$ in the decision-making gruops may not has the whole decision-making rule which groups possesses, that is parts of the decision rule are not owned by group $j$, which is called loss of decision-making rule. If there is a decision-making rule $R u_{i}=\left\{\right.$ rule $\left._{i}=\operatorname{des}\left([x]_{C_{i}}\right) \rightarrow \operatorname{des}\left([x]_{d_{i}}\right)\right\}$ in group, any one decision-making rule $R u_{i j}=\left\{\right.$ rule $_{i j}=\operatorname{des}\left([x]_{C_{i j}}\right)$ $\left.\rightarrow \operatorname{des}\left([x]_{d_{i j}}\right)\right\}$ of certain one group $j$ does not satisfy the conditions: $\operatorname{des}\left([x]_{C_{i j}}\right)=\operatorname{des}\left([x]_{C_{i}}\right)$ and $\operatorname{des}\left([x]_{d_{i j}}\right)$ $=\operatorname{des}\left([x]_{d_{i}}\right)$, then, decision-making rule $R u_{i}$ is an loss decision rule for group $j$. According to the formula (1) and (2), the support and credibility of decision rule are $S D_{i j}=0$ and $C D_{i j}=0$. However, certain support and credibility of decision-making rules is essentially not Zero. For example, when $\operatorname{des}\left([x]_{C_{i j}}\right) \cap \operatorname{des}\left([x]_{C_{i}}\right) \neq \varnothing$ 
and $\operatorname{des}\left([x]_{d_{i j}}\right) \cap \operatorname{des}\left([x]_{d_{i}}\right)=\varnothing$, the support and credibility of decision rule losses do not always equals Zero. Therefore, the amount of support and credibility of decision-making rule loss should depend upon the state of affair.

1) If group $j$ has one decision-making rule $R u_{i j}$ which can contain loss decision-making rule $R u_{i}$, and satisfies the condition of $\operatorname{des}\left([x]_{C_{i_{j}}}\right) \supset \operatorname{des}\left([x]_{C_{i}}\right)$ and $\operatorname{des}\left([x]_{d_{i j}}\right)=\operatorname{des}\left([x]_{d_{i}}\right)$, then the support and credibility of loss decision-making rule $R u_{i}$ is in accordance with the support and credibility of decision-making rule $R u_{i j}^{\prime}$, that is $S D_{i j}=S D_{i^{\prime} j}, C D_{i j}=C D_{i_{j}}$. For the purpose of group $j$, if there are $m$ ' decision-making rule $R u_{i j}$ which can contain the loss decision-making rule $R u_{i}$, then the support and credibility of loss decision-making rule $R u_{i}$ are as follow:

$$
S D_{i j}=\sum_{i=1}^{m^{\prime}} S D_{i^{\prime} j}, \quad C D_{i j}=\sum_{i^{\prime}=1}^{m^{\prime}} C D_{i^{\prime} j}
$$

2) If group $j$ has one decision-making rule $R u_{i j}$ which satisfies the condition of $\operatorname{des}\left([x]_{C_{i j}}\right)=\operatorname{des}$ $\left([x]_{C_{i}}\right)$ and $\operatorname{des}\left([x]_{d_{i j}}\right) \cap \operatorname{des}\left([x]_{d_{i}}\right)=\varnothing$, and the decision-making rule $R u_{i^{\prime} j}$ is restrict and incompatible to the loss decision-making rule $R u_{i}$, then the support and credibility of loss decision-making rule $R u_{i}$ are:

$$
S D_{i j}=0, C D_{i j}=0
$$

3) If group $j$ has no decision-making rule $R u_{i j}$ which satisfies the condition of $\operatorname{des}\left([x]_{C_{i j}}\right) \supseteq$ des $\left([x]_{C_{i}}\right), \operatorname{des}\left([x]_{d_{i j}}\right)=\operatorname{des}\left([x]_{d_{i}}\right)$ or $\operatorname{des}\left([x]_{d_{i j}}\right) \cap \operatorname{des}$ $\left([x]_{d_{i}}\right)=\varnothing$, then the loss decision-making rule is not relevant to the $R u_{i j}$, that is in the condition of $[x]_{C_{i j}}$, group $j$ has neither decision nor strategy, which is regarded as abstention in decision-making process. Therefore, the support and credibility of those kinds of loss decision-making rules to group $j$, are in accordance with emergency decision-making mechanism. Assuming to the above, the support and credibility of decision-making strategy to abstention in emergency decision-making process are meeting the condition as follow:

$$
S D_{i j}=0, C D_{i j}=0
$$

\subsection{Decision-Making Weight}

In the emergency response decision-making process, a number of factors influence the decision-making groups in decision weights, in which legal decision-making weight and expert decision-making weight are the two main factors. The mechanism of group decision-making to the legal decision-making weight is related with emergency decision-making mechanism; the mechanism of group decision-making to the expert decision-making weight is related with the credibility of expert groups. Those two weight response the emergency decisionmaking process, and demonstrate the laws of the following points:

1) The strategies of expert decision-making groups have more credibility and less ambiguous decision. The expert credibility enhances the decision-making weight of expert decision-making groups. The less ambiguous decision shows that there is less flexibility but more rigid in the decision-making, resulting in the more firm weight.

2) No matter how big groups of legal decision-making power, when it has ambiguous type of strategy and more decision-making room, legal decision-making weight will be greatly reduced. In order to meet decision-making target, decision makers may randomly adjust their strategy in order to influence their decision-making weight.

Therefore, in the process of emergency decision-making, group decision-making weight is in accordance with credibility of decision-making strategy. The more the credibility, the higher the decision-making weight, the less the credibility, the lower the decision-making weight. Hence, assuming that decision-making weight $\omega_{i j}$ of group $j$ in decision strategy $R u_{i j}$ is proportionate to credibility $C D_{i j}$ of the decision-making rule. Decision-making weight $\omega_{i j}$ of group $j$ in decision strategy $R u_{i j}$ can be represented by the relative credibility of decision-making rule $R u_{i j}$ to group $j$ :

$$
\omega_{i j}=e_{i j} / \sum_{j=1}^{n} e_{i j}=C D_{i j} / \sum_{j=1}^{n} C D_{i j}
$$

Then, the decision-making weight expectation of group $j$ in emergency decision-making process is: 


$$
e_{j}=\sum_{i=1}^{m} \omega_{i j} \cdot S D_{i j}
$$

After normalization of decision-making weight to each decision-making group in the group, it is available to get decision weights of the groups:

$$
\omega=\left(\omega_{1}, \omega_{2}, \cdots, \omega_{n}\right), \text { and } \omega_{j}=\frac{e_{j}}{\sum_{j=1}^{n} e_{j}}
$$

\subsection{Model of Information Relative Entropy Aggregation}

In process of emergency group decision-making, in order to obtain more efficient decision strategy, every group in the group want to choose the minimized deviation values of decision-making rules according to group decisionmaking rule. Therefore, the support $S D_{i}$ of group decision-making rule $R u_{i}$ can be computed by relative entropy aggregation model as Equation (9).

Where $\omega_{j}$ in (9) is the decision-making weight of group $j$, which can be computed by (8).

With nonlinear programming (9), local optimal solution $S D^{*}=\left(S D_{1}^{*}, S D_{2}^{*}, \cdots, S D_{m}^{*}\right)^{T}$ can be calculated, where $S D_{i}^{*}=\prod_{j=1}^{n}\left(b_{i j}\right)^{\omega_{j}} / \sum_{i=1}^{m} \prod_{j=1}^{n}\left(b_{i j}\right)^{\omega_{j}}, i=1,2, \cdots, m$, and $b_{i j}=S D_{i j} / \sum_{i=1}^{m} S D_{i j}$.

In the process of emergency group decision-making, $R u_{i}=\left\{\right.$ rule $\left._{i}=\operatorname{des}\left([x]_{C_{i}}\right) \rightarrow \operatorname{des}\left([x]_{d_{i}}\right)\right\}$ is one of group decision-making rules, where group credibility is $C D_{i}$.
If $\exists m^{*}$ decision-making rule meet the conditions as follows: $R u_{i}^{*}=\left\{\right.$ rule $\left._{i}^{*}=\operatorname{des}\left([x]_{C_{i}^{*}}\right) \rightarrow \operatorname{des}\left([x]_{d_{i}^{*}}\right)\right\} \quad$ and $\operatorname{des}\left([x]_{C_{i}^{*}}\right)=\operatorname{des}\left([x]_{C_{i}}\right), \operatorname{des}\left([x]_{d_{i}^{*}}\right) \neq \operatorname{des}\left([x]_{d_{i}}\right)$, and assuming that credibility of any decision-making rule $R u_{i}^{*}$ to group $j$ is $C D_{i^{*} j}$. Then, credibility $C D_{i}$ of any decision-making rule $R u_{i}^{*}$ can be calculated by relative entropy aggregation model (10) as follows:

Where $\omega_{j}$ in (10) is the decision-making weight of group $j$, which can be computed by (8).

With nonlinear programming (10), local optimal solution $C D^{*}=\left(C D_{1}^{*}, C D_{2}^{*}, \cdots, C D_{m^{*}}^{*}\right)^{T}$ can be calculated, where $C D_{i}^{*}=\prod_{j=1}^{n}\left(c_{i j}\right)^{\omega_{j}} / \sum_{i=1}^{m^{*}} \prod_{j=1}^{n}\left(c_{i j}\right)^{\omega_{j}}, i=1,2, \cdots, m^{*}$, and $b_{i j}=S D_{i j} / \sum_{i=1}^{m^{*}} S D_{i j}$.

From (9) and (10) it is known that $S D_{i j} \neq 0$ and $C D_{i j} \neq 0$ is not in conformity with the two kinds of decision-making loss situation, that is, in the situation of decision-making rule loss, support and credibility of group decision-making rule cannot be calculated by (9) and (10). To circumvent this problem, it is better to make infinitesimal positive real numbers to support and credibility of loss decision-making rule in decision-making rule loss situation as follows: $\ni \varepsilon \rightarrow 0$ and $\varepsilon \neq 0$, let $S D_{i j}=C D_{i j}=\varepsilon$.

\section{Case Study}

In the process of emergency decision-making, there are

$$
\left\{\begin{array}{l}
\min (S D)=\sum_{j=1}^{n} \omega_{j} \sum_{i=1}^{m}\left[S D_{i} \cdot\left(\log \left(S D_{i}\right)-\log \left(\frac{S D_{i j}}{\sum_{i=1}^{m} S D_{i j}}\right)\right)\right] \\
\text { s.t. } \sum_{i=1}^{m} S D_{i}=1
\end{array}\right.
$$

$$
\left\{\begin{array}{l}
\min (C D)=\sum_{j=1}^{n} \omega_{j} \sum_{i=1}^{m^{*}}\left[C D_{i} \cdot\left(\log \left(C D_{i}\right)-\log \left(\frac{C D_{i j}}{\sum_{i=1}^{m^{*}} C D_{i j}}\right)\right)\right] \\
\text { s.t. } \sum_{i=1}^{m^{*}} C D_{i}=1
\end{array}\right.
$$


Table 1. Decision-making table $T_{1}$.

\begin{tabular}{ccccccc}
\hline Decision-making rules & style & Position & Type & Decision & CD & SD \\
\hline$\omega_{1}$ & $\mathrm{Y}$ & $\mathrm{S}$ & $\mathrm{D}$ & accept & $75.00 \%$ & $9.09 \%$ \\
$\omega_{2}$ & $\mathrm{Y}$ & $\mathrm{S}$ & $\mathrm{D}$ & reject & $25.00 \%$ & $3.03 \%$ \\
$\omega_{3}$ & $\mathrm{Y}$ & $\mathrm{J}$ & $\mathrm{D}$ & accept & $50.00 \%$ & $9.09 \%$ \\
$\omega_{4}$ & $\mathrm{Y}$ & $\mathrm{J}$ & $\mathrm{D}$ & reject & $50.00 \%$ & $9.09 \%$ \\
$\omega_{5}$ & $\mathrm{Y}$ & $\mathrm{J}$ & $\mathrm{X}$ & accept & $33.33 \%$ & $6.06 \%$ \\
$\omega_{6}$ & $\mathrm{Y}$ & $\mathrm{J}$ & $\mathrm{X}$ & reject & $66.67 \%$ & $12.12 \%$ \\
$\omega_{8}$ & $\mathrm{P}$ & $\mathrm{S}$ & $\mathrm{D}$ & reject & $100.00 \%$ & $9.09 \%$ \\
$\omega_{9}$ & $\mathrm{P}$ & $\mathrm{X}$ & accept & $100.00 \%$ & $3.03 \%$ \\
$\omega_{11}$ & $\mathrm{P}$ & $\mathrm{J}$ & $\mathrm{D}$ & accept & $100.00 \%$ & $27.27 \%$ \\
$\omega_{13}$ & $\mathrm{P}$ & $\mathrm{J}$ & $\mathrm{X}$ & accept & $75.00 \%$ & $9.09 \%$ \\
$\omega_{14}$ & $\mathrm{P}$ & $\mathrm{J}$ & $\mathrm{X}$ & reject & $25.00 \%$ & $3.03 \%$ \\
\hline
\end{tabular}

Table 2. Decision-making table $T_{2}$.

\begin{tabular}{ccccccc}
\hline Decision-making rules & style & Position & Type & Decision & CD & SD \\
\hline$\omega_{1}$ & $\mathrm{Y}$ & $\mathrm{S}$ & $\mathrm{D}$ & accept & $100.00 \%$ & $20.59 \%$ \\
$\omega_{3}$ & $\mathrm{Y}$ & $\mathrm{J}$ & $\mathrm{D}$ & accept & $71.43 \%$ & $14.71 \%$ \\
$\omega_{4}$ & $\mathrm{Y}$ & $\mathrm{J}$ & $\mathrm{D}$ & reject & $28.57 \%$ & $5.88 \%$ \\
$\omega_{5}$ & $\mathrm{Y}$ & $\mathrm{J}$ & $\mathrm{X}$ & accept & $100.00 \%$ & $2.94 \%$ \\
$\omega_{10}$ & $\mathrm{P}$ & $\mathrm{S}$ & $\mathrm{X}$ & reject & $100.00 \%$ & $8.82 \%$ \\
$\omega_{11}$ & $\mathrm{P}$ & $\mathrm{J}$ & $\mathrm{D}$ & accept & $25.00 \%$ & $2.94 \%$ \\
$\omega_{12}$ & $\mathrm{P}$ & $\mathrm{J}$ & reject & $75.00 \%$ & $8.82 \%$ \\
$\omega_{14}$ & $\mathrm{P}$ & $\mathrm{J}$ & $\mathrm{X}$ & reject & $100.00 \%$ & $5.88 \%$ \\
$\omega_{15}$ & $\mathrm{Y}$ & $\mathrm{S}$ & $\mathrm{X}$ & accept & $90.00 \%$ & $26.47 \%$ \\
$\omega_{16}$ & $\mathrm{Y}$ & $\mathrm{S}$ & $\mathrm{X}$ & reject & $10.00 \%$ & $2.94 \%$ \\
\hline
\end{tabular}

Table 3. Decision-making table $T_{3}$.

\begin{tabular}{ccccccc}
\hline Decision-making rules & style & Position & Type & Decision & CD & SD \\
\hline$\omega_{1}$ & $\mathrm{Y}$ & $\mathrm{S}$ & $\mathrm{D}$ & accept & $85.71 \%$ & $14.29 \%$ \\
$\omega_{2}$ & $\mathrm{Y}$ & $\mathrm{S}$ & $\mathrm{D}$ & reject & $14.29 \%$ & $2.38 \%$ \\
$\omega_{3}$ & $\mathrm{Y}$ & $\mathrm{J}$ & $\mathrm{D}$ & accept & $50.00 \%$ & $4.76 \%$ \\
$\omega_{4}$ & $\mathrm{Y}$ & $\mathrm{J}$ & $\mathrm{D}$ & reject & $50.00 \%$ & $4.76 \%$ \\
$\omega_{5}$ & $\mathrm{Y}$ & $\mathrm{J}$ & $\mathrm{X}$ & accept & $50.00 \%$ & $7.14 \%$ \\
$\omega_{6}$ & $\mathrm{Y}$ & $\mathrm{J}$ & $\mathrm{X}$ & reject & $50.00 \%$ & $7.14 \%$ \\
$\omega_{7}$ & $\mathrm{P}$ & $\mathrm{S}$ & $\mathrm{D}$ & accept & $25.00 \%$ & $2.38 \%$ \\
$\omega_{8}$ & $\mathrm{P}$ & $\mathrm{S}$ & reject & $75.00 \%$ & $7.14 \%$ \\
$\omega_{12}$ & $\mathrm{P}$ & $\mathrm{J}$ & reject & $100.00 \%$ & $9.52 \%$ \\
$\omega_{13}$ & $\mathrm{P}$ & $\mathrm{J}$ & $\mathrm{X}$ & accept & $85.71 \%$ & $14.29 \%$ \\
$\omega_{14}$ & $\mathrm{P}$ & $\mathrm{J}$ & $\mathrm{X}$ & reject & $14.29 \%$ & $2.38 \%$ \\
$\omega_{15}$ & $\mathrm{Y}$ & $\mathrm{S}$ & $\mathrm{X}$ & accept & $90.00 \%$ & $21.43 \%$ \\
$\omega_{16}$ & $\mathrm{Y}$ & $\mathrm{X}$ & reject & $10.00 \%$ & $2.38 \%$ \\
\hline
\end{tabular}


four groups in the decision-making group, and the decision-making rules of the four groups are respectively listed in Tables 1-4. According to the four decision-making tables we can find that the four groups constituting a group have 15 decision-making rules, which are $\omega_{1}, \omega_{2}, \cdots, \omega_{15}$ respectively. The four groups all have decision-making loss in parts of their decision, therefore the support and credibility of four groups loss deci sion-making can be calculated by model (3),(4) and (5). According to model (6), (7) and (8), the results of decision making weight of four groups are $0.301,0.239,0.213$, 0.247 , respectively. Due to the fact that parts of support and credibility of loss decision-making are Zero, it influences the results of support and credibility of decision-making to the groups by using model (9) and (10). In order to eliminate this impact, we define that support and credibility of loss decision-making rule are alternated by $10^{-6}$. The results are shown in Table 5 as follows:

According to Table 5, after aggregating by relative entropy, the support and credibility of group decision-

Table 4. Decision-making table $T_{4}$.

\begin{tabular}{ccccccc}
\hline Decision-making rules & style & Position & Type & Decision & CD & SD \\
\hline$\omega_{1}$ & $\mathrm{Y}$ & $\mathrm{S}$ & $\mathrm{D}$ & accept & $28.57 \%$ & $5.71 \%$ \\
$\omega_{2}$ & $\mathrm{Y}$ & $\mathrm{S}$ & $\mathrm{D}$ & reject & $71.43 \%$ & $14.29 \%$ \\
$\omega_{3}$ & $\mathrm{Y}$ & $\mathrm{J}$ & $\mathrm{D}$ & accept & $25.00 \%$ & $2.86 \%$ \\
$\omega_{4}$ & $\mathrm{Y}$ & $\mathrm{J}$ & $\mathrm{D}$ & reject & $75.00 \%$ & $8.57 \%$ \\
$\omega_{5}$ & $\mathrm{Y}$ & $\mathrm{J}$ & $\mathrm{X}$ & accept & $50.00 \%$ & $5.71 \%$ \\
$\omega_{6}$ & $\mathrm{Y}$ & $\mathrm{J}$ & $\mathrm{X}$ & reject & $50.00 \%$ & $5.71 \%$ \\
$\omega_{9}$ & $\mathrm{P}$ & $\mathrm{S}$ & $\mathrm{X}$ & accept & $16.67 \%$ & $2.86 \%$ \\
$\omega_{10}$ & $\mathrm{P}$ & $\mathrm{S}$ & $\mathrm{X}$ & reject & $83.33 \%$ & $14.29 \%$ \\
$\omega_{12}$ & $\mathrm{P}$ & $\mathrm{J}$ & $\mathrm{D}$ & reject & $100.00 \%$ & $8.57 \%$ \\
$\omega_{13}$ & $\mathrm{P}$ & $\mathrm{J}$ & $\mathrm{X}$ & accept & $100.00 \%$ & $11.43 \%$ \\
$\omega_{15}$ & $\mathrm{Y}$ & $\mathrm{S}$ & $\mathrm{X}$ & accept & $100.00 \%$ & $20.00 \%$ \\
\hline
\end{tabular}

Table 5. The group decision-making rules.

\begin{tabular}{|c|c|c|c|c|c|c|c|c|c|c|}
\hline \multirow{3}{*}{$\begin{array}{l}\text { Decision- } \\
\text { making } \\
\text { rules }\end{array}$} & \multirow{2}{*}{\multicolumn{2}{|c|}{$\begin{array}{c}j=1 \\
0.301\end{array}$}} & \multirow{2}{*}{\multicolumn{2}{|c|}{$\begin{array}{l}j=2 \\
0.239\end{array}$}} & \multirow{2}{*}{\multicolumn{2}{|c|}{$\begin{array}{l}j=3 \\
0.213\end{array}$}} & \multirow{2}{*}{\multicolumn{2}{|c|}{$\begin{array}{l}j=4 \\
0.247\end{array}$}} & \multirow{2}{*}{\multicolumn{2}{|c|}{ group }} \\
\hline & & & & & & & & & & \\
\hline & $C D_{i 1}$ & $S D_{i 1}$ & $C D_{i 2}$ & $S D_{i 2}$ & $C D_{i 3}$ & $S D_{i 3}$ & $C D_{i 4}$ & $S D_{i 4}$ & $C D_{i}$ & $S D_{i}$ \\
\hline$\omega_{1}$ & $75.00 \%$ & $9.09 \%$ & $100.00 \%$ & $20.59 \%$ & $85.71 \%$ & $14.29 \%$ & $28.57 \%$ & $5.71 \%$ & $97.79 \%$ & $33.26 \%$ \\
\hline$\omega_{2}$ & $25.00 \%$ & $3.03 \%$ & $0 \%$ & $0 \%$ & $14.29 \%$ & $2.38 \%$ & $71.43 \%$ & $14.29 \%$ & $2.21 \%$ & $1.10 \%$ \\
\hline$\omega_{3}$ & $50.00 \%$ & $9.09 \%$ & $71.43 \%$ & $14.71 \%$ & $50.00 \%$ & $4.76 \%$ & $25.00 \%$ & $2.86 \%$ & $48.69 \%$ & $20.48 \%$ \\
\hline$\omega_{4}$ & $50.00 \%$ & $9.09 \%$ & $28.57 \%$ & $5.88 \%$ & $50.00 \%$ & $4.76 \%$ & $75.00 \%$ & $8.57 \%$ & $51.31 \%$ & $21.57 \%$ \\
\hline$\omega_{5}$ & $33.33 \%$ & $6.06 \%$ & $100.00 \%$ & $2.94 \%$ & $50.00 \%$ & $7.14 \%$ & $50.00 \%$ & $5.71 \%$ & $95.66 \%$ & $15.95 \%$ \\
\hline$\omega_{6}$ & $66.67 \%$ & $12.12 \%$ & $0 \%$ & $0 \%$ & $50.00 \%$ & $7.14 \%$ & $50.00 \%$ & $5.71 \%$ & $4.34 \%$ & $1.68 \%$ \\
\hline$\omega_{7}$ & $0 \%$ & $0 \%$ & $0 \%$ & $0 \%$ & $25.00 \%$ & $2.38 \%$ & $0 \%$ & $0 \%$ & $1.22 \%$ & 0.00\% \\
\hline$\omega_{8}$ & $100.00 \%$ & $9.09 \%$ & $0 \%$ & $0 \%$ & $75.00 \%$ & $7.14 \%$ & $0 \%$ & $0 \%$ & $98.78 \%$ & $0.10 \%$ \\
\hline$\omega_{9}$ & $100.00 \%$ & $3.03 \%$ & $0 \%$ & $0 \%$ & $0 \%$ & $0 \%$ & $16.67 \%$ & $2.86 \%$ & $61.34 \%$ & $0.09 \%$ \\
\hline$\omega_{10}$ & $0 \%$ & $0 \%$ & $100.00 \%$ & $8.82 \%$ & $0 \%$ & $0 \%$ & $83.33 \%$ & $14.29 \%$ & $38.66 \%$ & $0.09 \%$ \\
\hline$\omega_{11}$ & $100.00 \%$ & $27.27 \%$ & $25.00 \%$ & $2.94 \%$ & $0 \%$ & $0 \%$ & $0 \%$ & $0 \%$ & $7.93 \%$ & $0.16 \%$ \\
\hline$\omega_{12}$ & $0 \%$ & $0 \%$ & $75.00 \%$ & $8.82 \%$ & $100.00 \%$ & $9.52 \%$ & $100.00 \%$ & $8.57 \%$ & $92.07 \%$ & $0.88 \%$ \\
\hline$\omega_{13}$ & $75.00 \%$ & $9.09 \%$ & $0 \%$ & $0 \%$ & $85.71 \%$ & $14.29 \%$ & $100.00 \%$ & $11.43 \%$ & $69.49 \%$ & $2.12 \%$ \\
\hline$\omega_{14}$ & $25.00 \%$ & $3.03 \%$ & $100.00 \%$ & $5.88 \%$ & $14.29 \%$ & $2.38 \%$ & $0 \%$ & $0 \%$ & $30.51 \%$ & $0.81 \%$ \\
\hline$\omega_{15}$ & $0 \%$ & $0 \%$ & $90.00 \%$ & $26.47 \%$ & $90.00 \%$ & $21.43 \%$ & $100.00 \%$ & $20.00 \%$ & $98.79 \%$ & $1.68 \%$ \\
\hline$\omega_{16}$ & $0 \%$ & $0 \%$ & $10.00 \%$ & $2.94 \%$ & $10.00 \%$ & $2.38 \%$ & $0 \%$ & $0 \%$ & $1.21 \%$ & $0.03 \%$ \\
\hline
\end{tabular}


making rule change both. The support of decision-making $\omega_{1}$ is greatest, and its result is $33.26 \%$. The reason why it support is so high is because that supports of any groups in group to the decision-making rules are high, and the groups have higher degree of recognition acceptance. However, the support of decision-making $\omega_{7}$ is lowest, and its result is $0.003 \%$. The reason why it support is so low is because that recognitions of the decision-making rule in group lacks of consensus, and it only support by group $j=3$ but its support is just $2.38 \%$. The credibility of decision-making rule $\omega_{8}$ is greatest to group and its result is $98.78 \%$. Though group lacks of consensus in recognition to the decision-making rule, two groups $j=1$ and $j=3$ in decision-making groups have high support, even to a firm degree. The credibility of decision-making rule $\omega_{7}$ and $\omega_{16}$ is lowest to groups and their results are $1.22 \%$ and $1.21 \%$. The reason of low credibility in $\omega_{7}$ is that there is lacking of consensus in groups. The reason of low credibility in $\omega_{16}$ is that there is lacking of consensus in groups as well as believing that credibility of group is low in decision-making rule. The analysis result shows that group decision aggregation by relative entropy is feasible, scientific and reliable.

\section{Conclusions}

In the process of group decision-making in emergency management, information plays an important role to make effect decision strategies. This paper analyzes the information aggregation mechanism by using information relative entropy method, and believes that the law of information aggregation can be found out according to the information aggregation model.

\section{References}

[1] R. R. Yager, "On Ordered Weighted Averaging Aggregation Operators in Multicriteria Decision Making," IEEE Transactions on Systems, Man, and Cybernetics, Vol. 18, No. 6, 1988, pp. 183-190.

[2] S. E. Bodily, "A Delegation Process for Combining Indi- vidual Utility Function," Management Science, Vol. 25, No. 10, 1979, pp. 1035-1047.

[3] H. W. Brock, "The Problem of Utility Weights in Group Preference Aggregation," Operations Research, Vol. 18, No. 1, 1980, pp. 176-187.

[4] F. R. Krzyszto and S. L. Duck, "Preference Criterion for Flood Control under Uncertainty," Water Resources Research, Vol. 15, No. 3, 1979, pp. 513-520.

[5] D. F. Chen, Y. J. Lei and Y. Tian, "Aggregation and Application of the Information about Attribute Weights with Different Forms in Group Decision Making," Journal of Air Force Engineering University (Natural Science Edition) (in Chinese), Vol. 7, No. 6, 2006, pp. 51-53.

[6] B. J. Li, S. F. Liu, "A New Method on Group DecisionMaking with Interval-Number Judgment Matrices," Chinese Journal of Management Science (in Chinese), Vol. 12, No. 6, 2004, pp. 109-112.

[7] J. Wu and D. S. Huang, "The Uniform Methods for Interval Number Preference Information Multi-Attribute Decision Making," Systems Engineering-Theory Methodololgy Application (in Chinese), Vol. 12, No. 4, 2003, pp. 359-362.

[8] S. Z. Zhou, J. J. Zhu, S. F. Liu and H. H. Wang, "Goal Programming Model on Multiple Kinds of Uncertain Preference Aggregation Approach," Systems EngineeringTheory \& Practice (in Chinese), Vol. 3, 2008, pp. 118-124.

[9] J. J. Zhu, "Group Aggregation Approach of Two Kinds of Uncertain Preference Information," Control and Decision (in Chinese), Vol. 21, No. 8, 2006, pp. 889-892.

[10] X. Q. Feng, C. P. Wei, Z. Z. Li and G. Hu, "Aggregating of Interval Number Judgment Matrixes with Maximum Satisfaction," Systems Engineering (in Chinese), Vol. 24, No. 11, 2006, pp. 42-45.

[11] G. W. Wei, "Some Induced Geometric Aggregation Operators with Intuitionistic Fuzzy Information and their Application to Group Decision Making," Applied Soft Computing, Vol. 10, No. 2, 2010, pp. 423-431.

[12] H. J. Zimmermann and P. Zysno, "Decisions and Evaluations by Hierarchical Aggregation of Information," Fuzzy Sets and Systems, Vol. 10, No. 3, 1983, pp. 243-260.

[13] K. F. Xie and G. Chen, "Entrepreneurial Team's Risk Decision-Making Process Based on Group Learning," Computational Intelligence and Software Engineering (in Chinese), Vol. 2, No. 4, 2009, pp. 1-4. 